\title{
Behaviour of $E$-glass fibre reinforced vinylester resin composites under impact fatigue
}

\author{
RITA ROY, B K SARKAR* and N R BOSE \\ Department of Material Science, Indian Association for the Cultivation of Science, Kolkata 700 032, India \\ Central Glass and Ceramic Research Institute, Kolkata 700 032, India
}

\begin{abstract}
An impact fatigue study has been made for the first time on $63.5 \%$ glass fibre reinforced vinylester resin notched composites. The study was conducted in a pendulum type repeated impact apparatus especially designed and fabricated for determining single and repeated impact strengths. A well-defined impact fatigue (S-N) behaviour, having a progressive endurance below the threshold single cycle impact fracture stress with decreasing applied stress has been demonstrated. Fractographic analysis revealed fracture by primary debonding having fibre breakage and pullout at the tensile zone, but a shear fracture of fibre bundles at the compressive zone of the specimen. The residual strength, modulus and toughness showed retention of the properties at high impact stress levels up to 1000 impacts followed by a sharp drop. Cumulative residual stresses with each number of impacts not withstanding the static fatigue failure at long endurances have been ascribed for the composite failures under the repeated impact stresses.
\end{abstract}

Keywords. Impact fatigue; static fatigue; residual stress; $E$-glass fibre; vinylester resin.

\section{Introduction}

The failures of glass fibre reinforced composites under single and repeat impact (fatigue) has been of concern to the designers and users of aerospace structures. Notable amongst the failure modes observed is the delamination and debonding under impact (Sohn and $\mathrm{Hu}$ 1995). Amongst the large number of experimentation done on GFRP impact strength delamination and its predictions to failures by delamination have drawn some attention recently. Literature confirms the delamination effects under impact causing severe degradation of its tensile and compressive properties (Papanicolaou and Stavropoulus 1995). It thus emerges that the suitability of a composite under impact stresses is determined not only by the usual design parameters but also by the impact energy absorbing properties. The impact response is generally attributed to parameters like impact velocity, type of fibres and matrix used, fibre-matrix ratio and its interfacial bonding (Novak and Decrecent 1972). Fibre pullout and shear breakage, matrix cracking, debonding and delamination are few of the various types of damages that have been reported (Caprino 1983, 1984). Thus a great deal of the fibres' superior properties could not be taken advantage of. The failure process of composite laminates under static and fatigue loading is known to involve a sequential cumulation of damage in the form of a mixed dominated cracking. Most of the earlier studies were on the fatigue

\footnotetext{
*Author for correspondence
}

behaviour of composites involving measurements of fatigue life and stiffness reduction during fatigue loading (Talreja 1985; Davies et al 1996). The fatigue ratio (ratio of fatigue limit to the static fracture strain) was considered to be a useful index for rating fatigue properties of composites. Cumulative damage model with associated stiffness and strength reduction based on residual strength has been proposed (Talreja 1981). Matrix cracking as predominant failure mode has been reported by several investigators (Charewicz and Daniel 1975; Liu and Malvern 1987; Sierakowski et al 1982). In contrast Oever and Peijs (1998) demonstrated the cyclic fatigue behaviour of composites but the stiffness property was retained up to $95 \%$ of the single cycle strength.

The fatigue behaviour of composites under dynamic loading conditions is still an important research topic and far from being understood. Repeated four-point bending (Sun and Rechak 1988; Choi et al 1991) of GFRP with a stress ratio of 0.8 showed delamination and matrix cracking. The failure sequence was identified as nucleation and growth of superficial damage having fibre ridging, transverse as well as longitudinal matrix cracking. Sudden fibre bundle breakage and finally macroscopic delamination were observed. A strong interfacial bond between the fibre and resin matrix delayed the occurrence of fibre ridging and longitudinal matrix cracking, thus improving the overall fatigue performance of the composites. Progressive damage results in the loss of strength and stiffness of the composites and the loss of strength properties was related to the internal damage (Agarwal and Dally 1975). 
Several authors have studied the effects of notches and blowholes arising out of the processing (Boller 1957; Owen and Bishop 1972, 1973) on fatigue behaviour of GFRP. Notches were found to be more detrimental than blowholes. Blowholes acted like de-bonded sites and were responsible for initiating micro-cracks during early stages of fatigue in composites reinforced with uniaxial fibres. Although notches acted as stress raisers during tension cycle, but the fibres acted as crack arresters delaying ultimate failure.

Amongst the many studies made on the cyclic fatigue of composites there has been virtually none on impact fatigue of GFRP composites except one on borosilicate glass (Maity and Sarkar 1995) having significance to the reinforcing glass fibres. Therefore, an impact fatigue study has been designed to assess the ability of $E$-glass fibre reinforced vinylester composite material to withstand sudden application of repeated loads. The present work explores behaviour of the composites and its failure mode as a result of repeated impact stresses. Understanding of the basic fatigue failure mechanism during impact fatigue has been attempted.

\section{Experimental}

\subsection{Material}

$E$-glass fibres having density of $2.56 \mathrm{~g} / \mathrm{cm}^{3}$ and modulus of $72.35 \mathrm{GPa}$ were used as the reinforcing material in vinylester resin composites. The resin, a Bakellite Hylame product of grade HPR 8171 having density of $1.21 \mathrm{~g} / \mathrm{cm}^{3}$ and modulus of $2 \cdot 5-4 \mathrm{MPa}$ was used as the matrix material. MEKP, cobalt napthalene and $\mathrm{N}-\mathrm{N}$ dimethyl aniline were used as catalyst, accelerator and promoter, respectively.

\subsection{Sample preparation}

Samples with fibre rovings were prepared by taking 12 rovings of $E$-glass and soaked in vinylester resin with the catalyst, accelerator and promoter in $1: 1: 1$ ratio to the weight of the resin designated as GFRP 12. The soaked $E$-glass rovings were then pultruded by hand through a cylindrical glass tube of $\sim 180 \mathrm{~mm}$ length and $6 \mathrm{~mm}$ diameter. The samples were cured for $24 \mathrm{~h}$ at room temperature. The samples were then post cured at $80^{\circ} \mathrm{C}$ for $4 \mathrm{~h}$. The glass tube jacket was then broken and separated from the composite samples. Each rod was cut into pieces of $60 \mathrm{~mm}$ length for the mechanical and impact fatigue properties study. The weight of $E$-glass rovings was measured by weighing the cut samples followed by burning off the resin at $550^{\circ} \mathrm{C}$. The residue glass was then weighed. The percentage of glass fibre were determined by

$$
\left(W_{\mathrm{I}}-W\right) / W_{\mathrm{I}} \times 100
$$

where $W_{\mathrm{I}}$ is the weight of the composite (fibre + resin) and $W$ the weight of resin. Thus the percentage of glass fibre of the samples measured was $63.5 \%$. Notch on the samples were cut with a $0.3 \mathrm{~mm}$ thick diamond slitting blade according to the dimensions shown in figure 1, where the stress modes in the samples under impact is also incorporated.

\subsection{Test equipment}

A swinging pendulum type impact fatigue tester described earlier (Maity and Sarkar 1995; Sarkar and Glinn 1971) was designed and fabricated in the laboratory. Principally it consists of a rotating circular disc attached to a horizontal shaft on one end. The circular disc was rotated by a pulley and motor system. A pendulum type hammer arm with a cylindrical hammer was attached to the other end of the horizontal shaft. A trigger type mechanism was fixed to one side of the circular disc, which contacted the limit switch once during each revolution, thus registering the number of impacts. A spring-loaded pick up arm attached to the circular disc carried the pendulum hammer up to a predetermined angular height during the revolution. Upon contacting the preset trigger device the pick up arm retracted allowing the pendulum arm to drop on the specimen held horizontally between two tapered conical cups, screw mounted with the platform. After each impact the free hanging hammer was picked up again and released again till the specimen fractured.

Electrical circuit was so designed having a wire connection with the specimen grips. Upon specimen fracture the wire got detached deactivating the circuit thus stopping the machine. A 6-digit counter recorded the number of impacts.

\subsection{Impact test procedure}

A pendulum (length $30.5 \mathrm{~cm}$ ) and a hammer (weight $0.235 \mathrm{~kg}$ ) were used. Impact energy $(E)$ was calculated according to

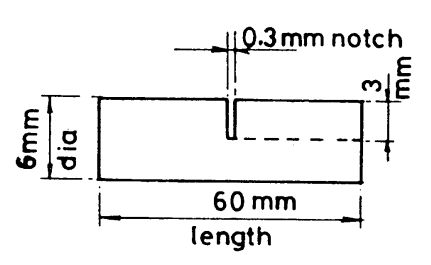

a) Sample dimension

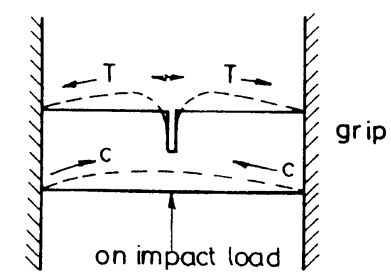

$T=$ Tensile stress $C=$ Compressive stress

(b) Under impact load
Figure 1. Sample dimensions with the development of tensile and compressive stresses on sudden impact load. 


$$
E=m g h(1-\cos \theta),
$$

where $m$ is the mass of the hammer, $g$ the gravitational constant, $h$ the length of the pendulum arm and $\theta$ the angle of hammer release.

Energy losses due to windage, friction and toss were determined as described earlier (Maity and Sarkar 1995). The impact energy imparted to the specimen was then obtained after subtracting the energy losses from the impact energy $E$ at $\theta$ angle of release of the hammer arm. Impact energy on the specimen was converted to stress $\sigma$, according to Maity and Sarkar (1995),

$$
\sigma=P / A+\sqrt{ }\left(P^{2} / A^{2}+2 Y E / A l\right)
$$

where $A$, and $l$ are cross-sectional area and length of the sample respectively, $P$ the load, $E$ the impact energy after accounting for the energy losses due to windage, friction and toss and $Y$ the elastic modulus.

For impact fatigue test, the angle was set at a decreasing interval of $10^{\circ}$ below the angle required for single impact failure. Tests were terminated at just above $10^{5}$ impacts. Flexural strengths were measured for both notch and un-notched samples under the three-point bend tests in Instron 4303 universal testing machine with a span of $50 \mathrm{~mm}$ at cross head speed of $5 \mathrm{~mm} / \mathrm{min}$. Flexural strength $\left(\sigma_{\mathrm{f}}\right)$ was measured using the standard beam formula

$$
\sigma_{\mathrm{f}}=8 S P / \pi d^{3}
$$

where $S$ is the span length, $P$ the breaking load and $d$ the diameter of the samples. A typical load extension curve is shown in figure 2.

Repeated impacts did not break the specimens into two halves but a white patch of debonded zone appeared

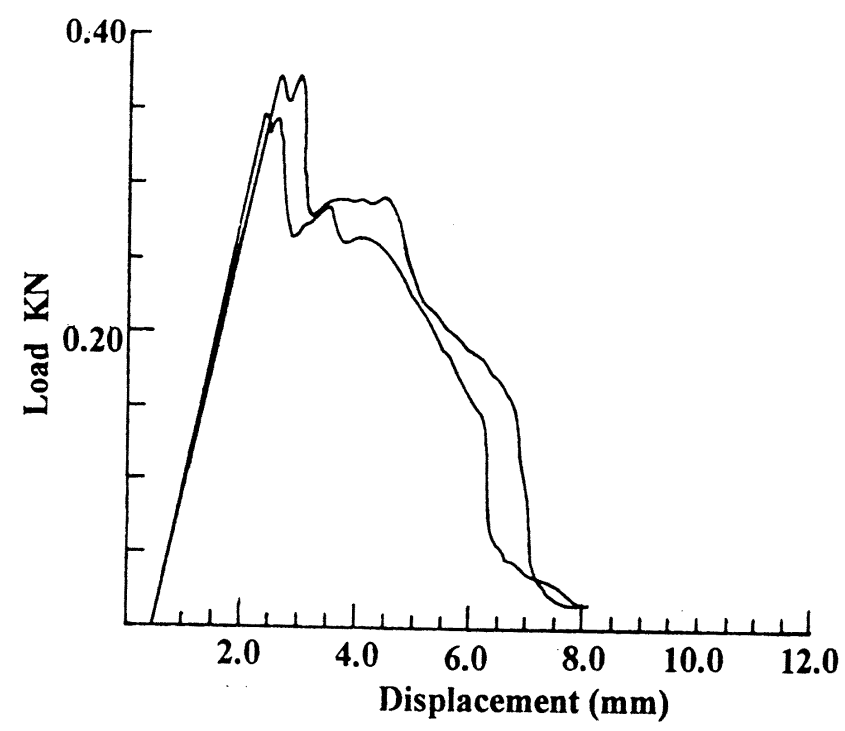

Figure 2. Load-displacement curve of GFRP 12 composite. that increased progressively under impact fatigue tests. At the single point impact by the hammer with the ends under the grips the sample experiences two stress modes imposed suddenly, described schematically in figure 1. At one half of the sample at the notch zone the stress is tensile whilst at the opposite end, at the point of contact between the hammer and sample, the stress is compressive arising out of bending moment. Repeated impacts were terminated when the debonded zone spread longitudinally to a predetermined length of $10.6 \mathrm{~mm}$. The fatigued samples were then measured for residual properties in the Instron 4303 under three-point bending.

\section{Results and discussion}

The set of mechanical properties of the un-notched and notched unidirectional composite samples are given in table 1 . The values of the notched samples were nearly half of that of un-notched samples except for the toughness and energy to break point having virtually no change. Examination of the load vs strain curve obtained for the un-notched samples in figure 2 revealed an increase in strain at a constant yield stress of $370 \mathrm{MPa}$ before the load dropping off sharply with fibre fracture and pull out. The composites were able to sustain an amount of $1.5 \%$ strain before fracture took place. The fracture did not run through the samples to separate the pieces into two halves.

Figure 3 shows an $\mathrm{S}-\mathrm{N}$ type impact fatigue curve obtained for GFRP 12 composites. Interestingly the curve displayed four regions in contrast to three regions shown by Talreja (1995) and Hashin and Rotem (1973).

The region I showed a progressive increase in endurance to 20 odd impact cycles for a small drop in applied impact stress at the high stress zone arising out of the matrix failure of the sample surface at the point of impact as the stress was taken up by the reinforcing fibres. The rest three regions are similar to the findings of the other workers (Hashin and Rotem 1973) having a plateau (region II) at applied impact stresses of 110-90 MPa when the samples endured around 500 impact cycles. This is followed by progressive endurance to the extent of 1000 impact cycles with decreased impact stresses from 95-60 MPa (region III) and an endurance limit (region IV) at around $50 \mathrm{MPa}$. The composites were measured

Table 1. Mechanical properties of un-notched and notched GFRP 12 composites.

\begin{tabular}{lcc}
\hline Mechanical properties & Un-notched & Notched \\
\hline Stress at yield (MPa) & $623 \cdot 2$ & $371 \cdot 1$ \\
Modulus (MPa) & 21370 & 11190 \\
Breaking energy (J) & 0.9762 & 0.5191 \\
Toughness (MPa) & $0 \cdot 0442$ & 0.0430 \\
\hline
\end{tabular}


for their single impact failure and had values of 150 $160 \mathrm{MPa}$. A drop of applied impact stress by $20 \%$ of single impact strength showed an endurance of 15-19 cycles and at $31 \%$ the endurance limit was reached. A plot of maximum impact stress normalized with respect to single impact strength against endurance is compared with the observations made by Oever and Peijs (1998) and shown in figure 4.

Our results compare well with them (Hashin and Rotem 1973; Oever and Peijs 1998) except for the endurance being lower. A plot on a logarithmic scale to derive a correlation between single impact strength and fatigue strength showed a simple straight line relationship (figure 5).

The S-N curve could be expressed by the linear regression analysis and found to be a simple power law of the form,

$$
\sigma^{n} N=A,
$$

where $\sigma$ is the impact stress and $A$ a constant. The value of exponent ' $n$ ' was 11.17 indicative of a fatigue resistance of the composite material. During impact fatigue testing, each impact produces a shock wave which induces

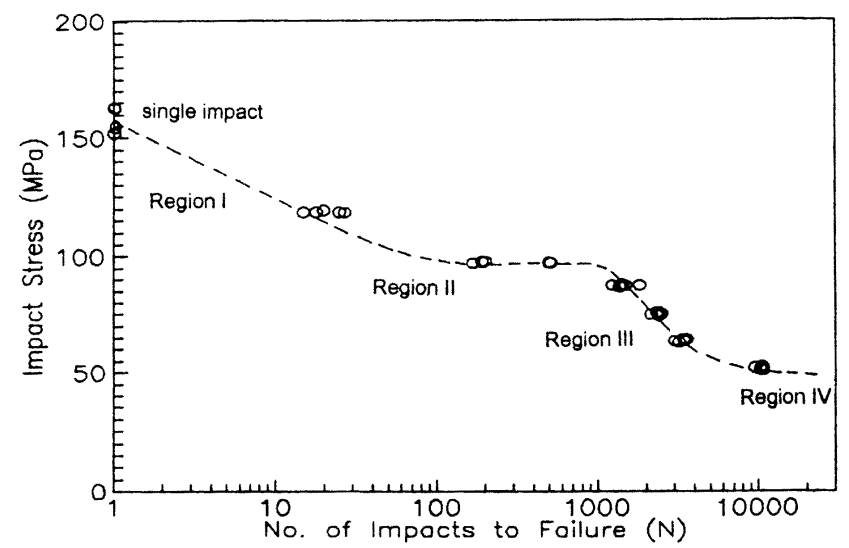

Figure 3. Impact fatigue (S-N) curve of GFRP 12 composite.

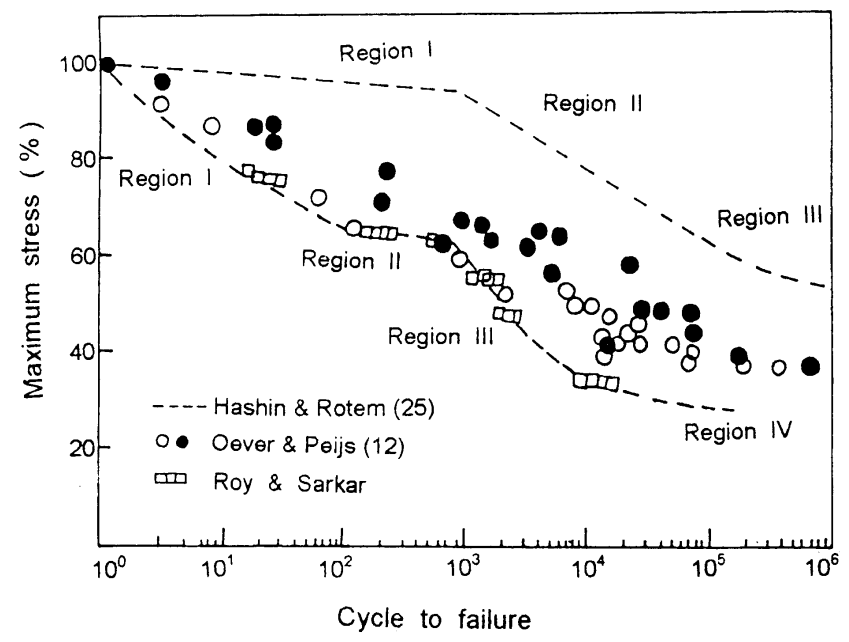

Figure 4. Normalized impact fatigue curves. greater damage than the slow cyclic stressing to the same level as performed in conventional fatigue tests, defining the value ' $n$ '.

\subsection{Residual strength properties}

The impact fatigued samples were measured for their residual strength, modulus and toughness properties. The results obtained are shown in figures 6,7 and 8 respectively. The mean curves drawn through the values obtained displayed a very shallow drop of properties till about $10^{3}$ impact cycles after which the drops were very steep. However, after initial 20 impact cycles there had been a drop of strength by about $24 \%$ from bend strengths, $28 \%$ for modulus and only $10 \%$ for toughness.

The appearance of a well defined length of $10.6 \mathrm{~mm}$ white debonded patch at the zone of impacts for a number of impact cycles was taken to be the limit before taking the samples for residual strength measurements. By this criteria the damage would have been the same for all samples at all stress levels investigated and for any

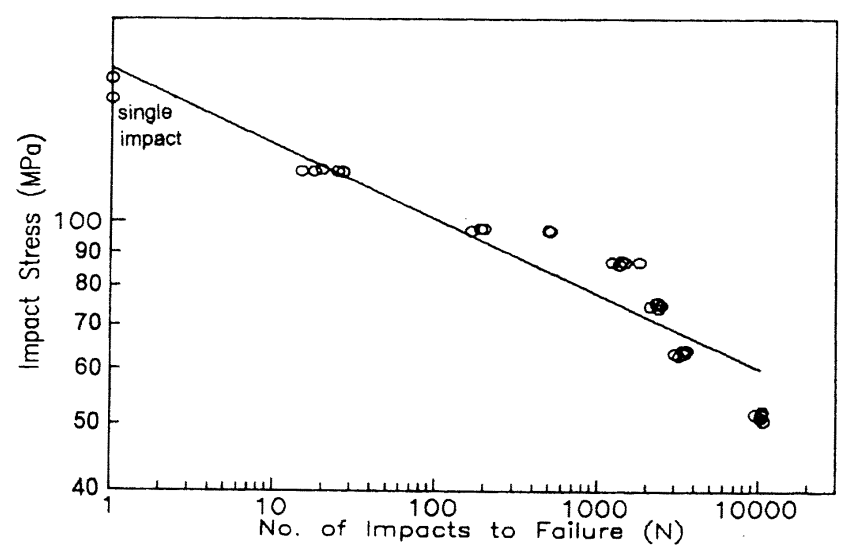

Figure 5. S-N curve of GFRP 12 composite on log-log scale.

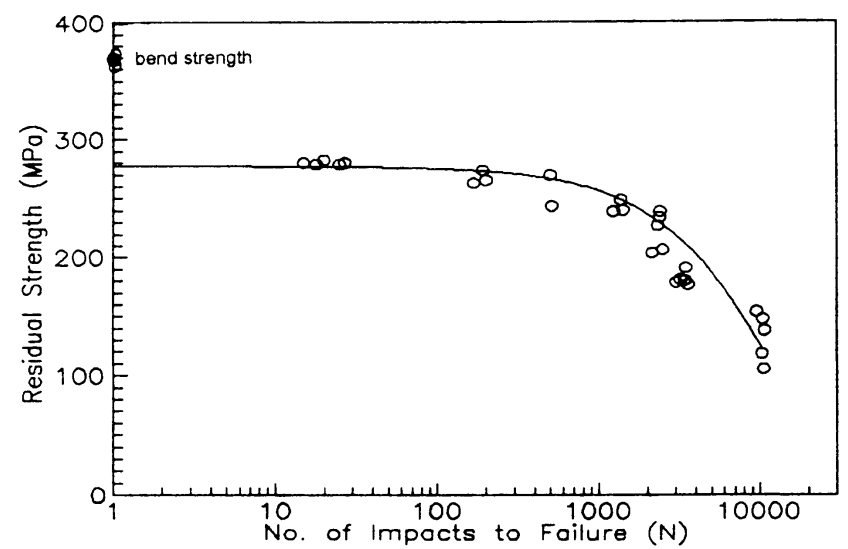

Figure 6. Residual strength of GFRP 12 composite after impact fatigue. 
number of impacts endured. Consequently the residual properties would have been the same. However, the results reflected differently having around $280 \mathrm{MPa}$ residual strength at 20-100 impact cycles and 210$240 \mathrm{MPa}$ at 2000 impact cycles dropping to $110-140 \mathrm{MPa}$ at 10,000 impact cycles (figure 6). The modulus and toughness values obtained showed similar features with a drop from $8300 \mathrm{MPa}$ at 20 cycles to $5200 \mathrm{MPa}$ at 2000 to $3100 \mathrm{MPa}$ at 10,000 impact cycles (figure 7) and 0.035$0.020 \mathrm{MPa}$ drop for 2000 impact cycles to $0.012 \mathrm{MPa}$ at 10,000 impact cycles (figure 8) respectively.

It is apparent from these observations that initially there had been matrix cracking and debonding but the fibres were not damaged sufficiently thereby sustaining the impact stress till 1000 impact cycles. Thereafter the fibres got sufficiently damaged retaining virtually no strength. This gestation period where the strengths have been sustained inspite of debonding and delamination with matrix cracking at the area of impacts could be attributed to the slow cumulative development of residual stresses finally reaching the critical breaking stress of the fibres at above 10,000 cycles. The time period the glass fibres were under stress for the static fatigue phenomena to be operative (Talreja 1981) in combination with dynamic

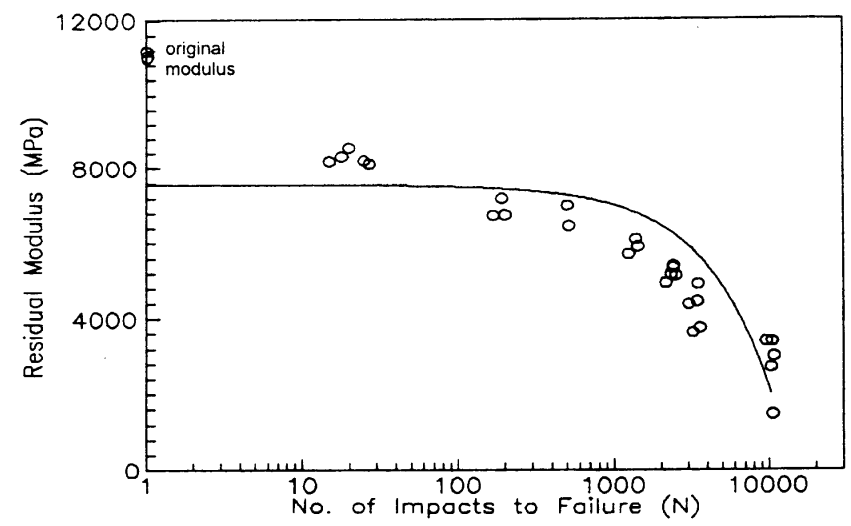

Figure 7. Residual modulus of GFRP 12 composite after impact fatigue.

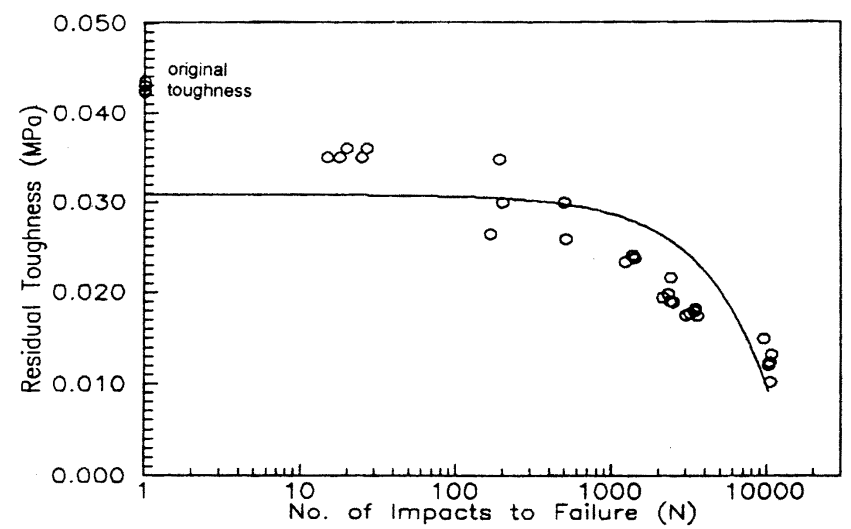

Figure 8. Residual toughness of GFRP 12 composite after impact fatigue. fatigue (Oever and Peijs 1998) could equally contribute to the subsequent deterioration of properties.

\subsection{Fractographic analysis}

Samples broken for residual strength measurements showed fibre pullout and breakage at the notch zones, shown in figure 9. At the interior where the impact stresses were predominant, shear breakage of the fibre bundles (Sun and Rechak 1988; Choi et al 1991) were seen to occur as shown in figure 10. It was observed that the width of the fibre pull out and breakage got reduced and the fibre bundle fracture increased with increased endurance at a decreasing applied impact stress. Under single point impact loading the sample experiences two types of stress mode; tensile stresses at the notch end and compressive stresses at the impact end depicted in figure 1. The debonding, fibre pull out and fracture are the result of tensile stresses corresponding to a normal tensile test. But the fibre bundle fracture is indicative of compressive

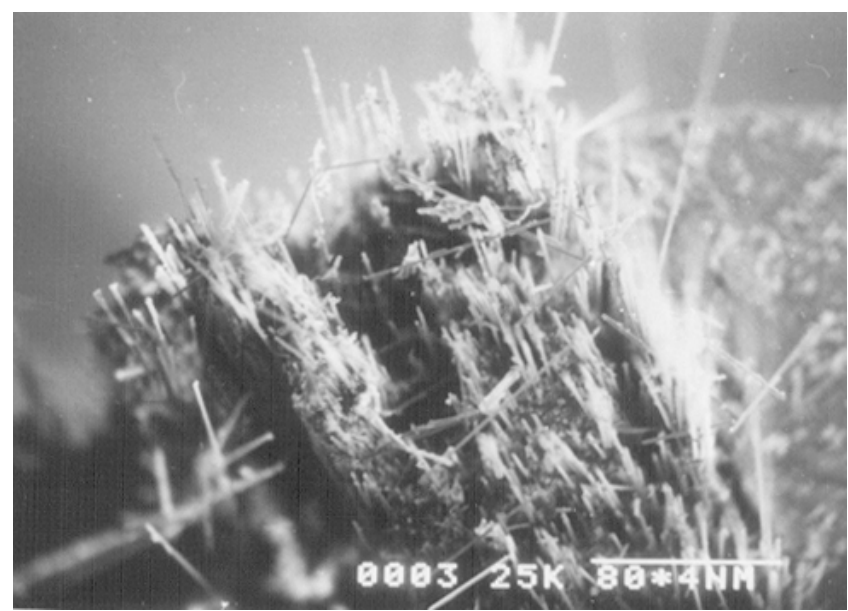

Figure 9. SEM of GFRP 12 specimen showing fibre pull-out and breakage at the notch zone after 20 cycles.

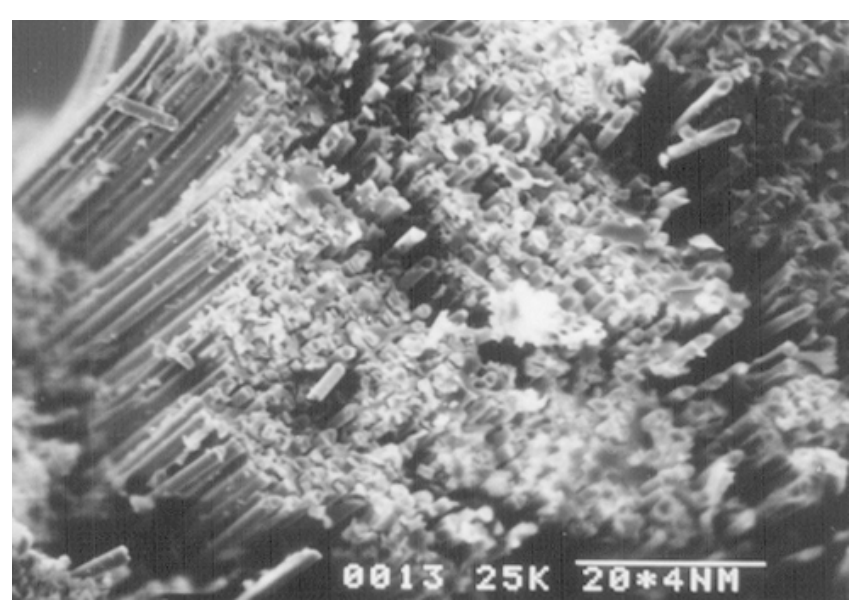

Figure 10. SEM of GFRP 12 specimen showing the shear breakage of the fibre bundles after 3015 cycles. 
stress failure. With increasing number of impact cycles micro and macro damages cumulated in the fibres till the critical fracture stress was reached. Since the glass fibre is a major constituent in reinforcing composites having susceptibility to static fatigue phenomena the time the fibres were under stress causing damage is meaningful.

The four regions (figure 3) of the fatigue behaviour could thus be attributed to the initial damage of the resin matrix which took the heavy impact load (region I). It caused the initial drop of residual properties for an endurance of 20 impact cycles. This is in agreement with the observations (Sarkar 1998) that the composites can accommodate nearly $30 \%$ damage in glass-fibre reinforced matrix without affecting the composite strength whilst a small volume\% of defects in fibres affects the composites very seriously. The reinforcing fibres in this region remained undamaged. Some propagation of the damage in the form of debonding and delamination occurred without affecting the bulk of the samples. The impact stress cycles being accommodated by the fibres and the residual good addition between the fibres and the resin matrix. As the progressive endurance increased at lower subcritical stress level (region II) the failure had been due to primary debonding occurring in larger volume across the samples. The fibre damage began to occur once the number of impact cycles reached sufficient numbers and a combined matrix and fibre damages predominated giving rise to the rapid weakening of the composites (region III). The fibre damage was the consequence of the cumulative residual stresses and any moisture affecting its strength. The time the fibres were under such stresses especially at long endurances was sufficiently damaging not to retain any residual strength properties. Finally in region IV where the impact stress cycles were inadequate to cause sufficient damage to the fibre and resin matrix sustaining the composite for an endurance limit.

\section{Conclusions}

An impact fatigue curve for the glass fibre reinforced vinylester resin composites has been demonstrated for the first time. The composite samples showed progressive endurance below the threshold fracture stress with decreasing applied impact stresses having an endurance limit at around $31 \%$ of the single impact failure stress. Measurements of the residual strength, modulus and toughness properties showed an initial drop in properties after enduring only 20 odd impact cycles caused by matrix cracking only. Thereafter the composites endured around 1000 impact cycles without much change in residual properties followed by a rapid drop. Cumulation of residual stresses on each impact causing delamination and debonding initially followed by fibre damage have been attributed to the cause for the impact fatigue failures. Microstructural studies revealed severe debonding with fibre pull out and fracture at the tensile zone whilst shear fracture of fibre bundles was seen to occur at the compressive zone of the composite samples.

\section{Acknowledgements}

The authors are indebted to the Council of Scientific and Industrial Research, New Delhi, for providing financial assistance during the course of investigation. Sincere thanks are due to $\mathrm{Mr} \mathrm{S} \mathrm{K} \mathrm{Dalui} \mathrm{and} \mathrm{Mr} \mathrm{K}$ Banerjee, Central Glass and Ceramic Research Institute, Kolkata and Mr A K Rana and Mrs M Sarkar, Indian Jute Industries Research Association, Kolkata for their unstinted support. The Director, Indian Association for the Cultivation of Science, Kolkata, is acknowledged for his interest and support.

\section{References}

Agarwal B D and Dally J W 1975 J. Mater. Sci. 10193

Boller K H 1957 Modern Plastics 34163

Caprino G 1983 J. Mater. Sci. 182269

Caprino G 1984 J. Compos. Mater. 18508

Charewicz A and Daniel I M 1975 in Composites materials fatigue and fracture, ASTM STP 586 p. 92

Choi H Y, Wu H Y T and Chang F K 1991 J. Compos. Mater. 251012

Davies G A O, Hitchings D and Zhou G 1996 Composites A27 1147

Hashin Z and Rotem A 1973 J. Compos. Mater. 7448

Liu D and Malvern L E 1987 J. Compos. Mater. 21594

Maity S and Sarkar B K 1995 Bull. Mater. Sci. 18857

Novak R C and Decrecent M A 1972 in Impact behaviour of unidirectional composites, ASTM STP (Philadelphia, PA: American Society for Testing and Materials) 497 p. 311

Oever Van den M and Peijs T 1998 Composites A29 227

Owen M J and Bishop P T 1972 J. Phys. D5 1621

Owen M J and Bishop P T 1973 J. Phys. D6 2057

Papanicolaou G C and Stavropoulus C D 1995 Composites 26 517

Sarkar B K 1998 Bull. Mater. Sci. 21329

Sarkar B K and Glinn T G J 1971 J. Mater. Sci. 54601

Sierakowski R L, Malvern L E and Takeda N 1982 in Microscopic observations of cross-sections of impacted composite laminates, Composite technology review, ASTM STP (Philadelphia, PA: American Society for Testing and Materials) p. 40

Sohn M S and Hu X Z 1995 Composites 26849

Sun C T and Rechak S 1988 in Effect of adhesive layers on impact damage in composite laminates, Composite materials: Testing and design, ASTM STP (Philadelphia, PA: American Society for Testing and Materials) 972 p. 97

Talreja R 1981 Proc. R. Soc. London A378 461

Talreja R 1985 J. Comp. Tech. Res. 725

Talreja R 1995 Mater. Sci. \& Eng. A200 21 